\title{
Risk factors for large-for-gestational age infants in pregnant women with type 1 diabetes
}

\author{
Astrid Morrens ${ }^{1}$, Johan Verhaeghe ${ }^{2}$, Christine Vanhole ${ }^{3}$, Roland Devlieger ${ }^{2}$, Chantal Mathieu'
} and Katrien Benhalima ${ }^{* *}$

\begin{abstract}
Background: The rate of neonatal overweight remains generally high in type 1 diabetes (T1DM). Since glycemic control has improved over time other contributors need to be identified. Our aim is to evaluate the risk factors for large-for-gestational age infants (LGA) in women with T1DM and to evaluate whether the rate of LGA decreased over time.

Methods: Retrospective analysis of the medical files of pregnant women with T1DM attending our university hospital form 01-01-1992 till 31-07-2014. The generalized mixed model was used to adjust for several pregnancies over time in the same women. A multivariable model was used to evaluate independent risk factors for LGA.

Results: Over a 22-year period, 259 pregnancies in 180 T1DM women were identified. Mean diabetes duration of women was $13.7 \pm 7.1$ years, with a mean age of $29.5 \pm 5.2$ years. Macrosomia $(>4 \mathrm{Kg}$ ) was present in $16.2 \%$ of deliveries, LGA was present in $45.2 \%$ and these numbers did not change over time (resp. $p=0.19$ and $p=0.70$ ). Over time, significant more women were overweight (23.3\% vs. $39.3 \%, p=0.009)$ and more women had excessive weight gain during pregnancy ( $21.3 \%$ vs. $37.7 \%, p=0.019)$. Compared to women with a non-LGA baby, women with a LGA baby had a higher weight at delivery ( $84.1 \pm 11.1$ vs. $80.4 \pm 10.8, p=0.016)$, had more often excessive weight gain ( $45.3 \%$ vs. $25.2 \%, p=0.003$ ) and had less strict glycaemic control in the first and third trimester [HbA1c of resp. $49 \pm 10 \mathrm{mmol} / \mathrm{mol}(6.7 \% \pm 0.9)$ vs. $47 \pm 8 \mathrm{mmol} / \mathrm{mol}(6.5 \% \pm 0.8), p=0.01$ and $44 \pm 5 \mathrm{mmol} / \mathrm{mol}$ $(6.2 \% \pm 0.5)$ vs. $42 \pm 6 \mathrm{mmol} / \mathrm{mol}(6.0 \% \pm 0.6), p=0.01]$. In the forward multivariable analysis, excessive weight gain [OR $1.95(1.08-3.53), p=0.027$ ], HbA1c level in early [OR $1.43(1.05-1.95), p=0.023$ ] and late pregnancy [OR 1.70 $(1.07-2.71), p=0.026]$ remained independent predictors for LGA.

Conclusions: LGA remains a frequent complication in T1DM. Excessive weight gain and HbA1c in early and late pregnancy are important risk factors for LGA in our population. These findings highlight the importance of strict maternal glycemic control and simultaneous striving to appropriate gestational weight gain to minimize the risk of fetal overgrowth in T1DM pregnancies.
\end{abstract}

Keywords: Type 1 diabetes, Pregnancy, Weight gain, Large-for-gestational age infants

\footnotetext{
* Correspondence: katrien.benhalima@uzleuven.be

'Department of Endocrinology, UZ Gasthuisberg, KU Leuven, Herestraat 49,

Leuven 3000, Belgium

Full list of author information is available at the end of the article
}

\section{Ciomed Central}

(c) 2016 The Author(s). Open Access This article is distributed under the terms of the Creative Commons Attribution 4.0 International License (http://creativecommons.org/licenses/by/4.0/), which permits unrestricted use, distribution, and reproduction in any medium, provided you give appropriate credit to the original author(s) and the source, provide a link to the Creative Commons license, and indicate if changes were made. The Creative Commons Public Domain Dedication waiver (http://creativecommons.org/publicdomain/zero/1.0/) applies to the data made available in this article, unless otherwise stated. 


\section{Background}

Due to improved medical care, outcomes in pregnant women with type 1 diabetes (T1DM) have improved substantially over the past decades [1-3]. Nevertheless, the prevalence of macrosomia continues to increase [4]. Macrosomia can cause major problems during labor and is associated with increased neonatal morbidity as well as long-term increased risk of developing overweight and type 2 diabetes (T2DM) [5]. Neonatal overweight in T1DM is mainly caused by placental transfer of maternal glucose but since glycemic control has improved over time other contributors need to be identified [6]. In healthy pregnant women obesity and excessive weight gain in pregnancy predispose to macrosomia [7, 8]. Most studies on this topic in women with diabetes include T2DM patients or women with gestational diabetes (GDM) and confirm the strong association between obesity, excessive weight gain in pregnancy and fetal overgrowth $[9,10]$. On women with T1DM the evidence is far more scarce. A large Swedish cohort study in T1DM patients showed a positive relation between high pre-pregnancy body mass index (BMI) and the risk of fetal overgrowth [11]. Recently an observational study identified excessive weight gain during pregnancy as an independent risk factor for fetal overgrowth in T1DM patients [12]. The aim of this study was therefore to evaluate the risk factors for large-for-gestational age infants (LGA) in our T1DM population and to evaluate whether the rate of LGA decreased over time. Our hypothesis was that the increasing prevalence of maternal overweight and excessive gestational weight gain, independently of maternal glycemic control, might contribute to the persistent high prevalence of LGA in women with T1DM.

\section{Methods}

Analysis of the electronic medical files over a 22 year period from 01-01-1992 till 31-07-2014 of all pregnant women with T1DM attending the University Hospital UZ Leuven. The study was approved by the Institutional Review Board of UZ Leuven (ML 10676). Our study adheres to the Helsinki Declaration of 1975. Due to the retrospective nature of the study there was no need for informed consent from the participants as in compliance with the Belgian Law of December 8,1992 on the protection of privacy and the Belgian Law of August 22, 2002 on the rights of the patient.

Since 1999 a structured electronic medical file is used in our center. From 1992 till 2012 data were prospectively collected in the database. From 2012 onwards all data were retrospectively collected. Due to lack of data from women with late referrals, only pregnant T1DM women with antepartum follow-up $<12$ weeks at UZ Leuven were included in the study. Other exclusion criteria were women with GDM, T2DM, hereditary diabetes, secondary diabetes and use of a peritoneal insulin infusion pump. Because we aimed to analyze the risk factors for LGA, we only included life births and single births, also excluding women with abortion due to congenital malformations, mors in utero and multiple births.

UZ Leuven Hospital is a tertiary care facility with an average of 2400 deliveries per year and is equipped with a High Risk Obstetrics department. Women with T1DM are intensively followed up during and after pregnancy by a multidisciplinary team with an experienced diabetologist, obstetrician and neonatologist using standardized protocols. Women with T1DM are advised to carefully plan their pregnancy. In our center, women with active pregnancy wish are therefore seen monthly at the multidisciplinary diabetes clinic with an experienced diabetologist, diabetes nurse and dietician. The general policy in our center is that contraception can only be stopped when an HbAlc $<53 \mathrm{mmol} / \mathrm{mol}(7 \%)$ is achieved during at least two consecutive monthly controls. If feasible, a pre-pregnancy $\mathrm{HbA} 1 \mathrm{c}<48 \mathrm{mmol} / \mathrm{mol}$ (6.5 \%) is aimed for. When planning pregnancy and during pregnancy, women are asked to perform selfmonitoring of plasma glucose seven times daily (before and $2 \mathrm{~h}$ after each meal and at bedtime.). The glycemic targets used in pregnancy are fasting and premeal 3.3$5.5 \mathrm{mmom} / \mathrm{l}, 2 \mathrm{~h}$ postprandial $<6.7 \mathrm{mmol} / \mathrm{l}$ and before bedtime $6.0-8.0 \mathrm{mmol} / \mathrm{l}$. From the second trimester on an $\mathrm{HbA} 1 \mathrm{c} \leq 42 \mathrm{mmol} / \mathrm{mol}(6 \%)$ is aimed for. Once pregnant, women are seen two weekly at the multidisciplinary diabetes clinic. In our center an insulin pump is the preferred treatment to optimize glycemic control in pregnancy, unless excellent control on multiple daily injections (MDI). Most women with T1DM are therefore already treated with an insulin pump before pregnancy. As short acting insulin the insulin analogues Aspart or Lispro are used. For women on MDI, since 2011 insulin Detemir is preferably used over insulin Glargine as the long acting insulin analogue. Metformin is rarely used during pregnancy in T1DM in our center and when used this is discontinued at the end of the first trimester.

After the obstetrical booking visit at 6-8 gestational weeks, pregnant T1DM women come for an antepartum visit every 4 weeks until 20-22 gestational weeks, every 2 weeks until 32 gestational weeks and subsequently weekly or twice weekly until delivery. Routine non-stress tests are performed at all visits from 32 gestational weeks onwards and all patients receive a minimum of three ultrasound evaluations. After an uneventful pregnancy, induction of labor is offered to the large majority of women at 38 gestational weeks. In case of complications, particularly hypertension, women are seen at least twice-weekly at the day-ward or admitted to the antepartum ward; the timing of delivery is individualized in 
these cases. Indications for caesarean section, apart from routine obstetrical indications (breech, etc.), include previous caesarean section and an unfavorable cervix, fetal weight estimated to be LGA on the basis of the abdominal circumference measurement, and severe maternal disease. Over the 22 year follow up period the same standardized protocols were used, except for changes in policy concerning the peripartum glycemic control and hospitalization at the neonatal intensive care. More specifically, since 1999 a strict glycemic control was aimed for during labor and delivery with preferably continuation of the insulin pump. Since the year 2005, provided that the Apgar scores were satisfactory and gestational maturity was achieved, most neonates stay with their mother. Before 2005 almost all neonates were preventively hospitalized at the neonatology department for a few days.

Outcomes were obtained from review of the electronic database. Maternal characteristics recorded were age, ethnicity, weight, BMI at first prenatal visit, overweight $\left(\right.$ BMI $\geq 25$ and $\left.<29.9 \mathrm{Kg} / \mathrm{m}^{2}\right)$, obesity $\left(\mathrm{BMI} \geq 30 \mathrm{Kg} / \mathrm{m}^{2}\right)$, weight gain (difference in weight between first prenatal visit and the delivery) and parity. Excessive weight gain was defined according to the most recent Institute of Medicine (IOM) guidelines [13]. Other maternal data that were recorded are: rates of preconception consultation, intake of folium acid (started before or in the first trimester), need for fertility treatment, smoking during pregnancy, diabetes duration, year of delivery, insulin dose $(\mathrm{Unit} / \mathrm{kg} / 24 \mathrm{~h})$ in each pregnancy trimester, type of insulin treatment (insulin pump or MDI), HbA1c before pregnancy, $\mathrm{HbA1c}$ in each pregnancy trimester (preferably at week 8 , week 21 and week 36). Other data collected are the lipid profiles (mostly non-fasting) up to 1 year before pregnancy or in the first trimester (total cholesterol, triglycerides, HDL cholesterol and LDL cholesterol), the blood pressure at week 8 , known diabetic retinopathy, known diabetic nephropathy $(24 \mathrm{~h}$ microalbuminuria $>30 \mathrm{mg}$ ) and use of steroids.

The following maternal pregnancy outcomes were recorded: pregnancy induced hypertension (PIH) (blood pressure $\geq 140 / 90 \mathrm{mmHg}$ ), preeclampsia (hypertension + proteinuria or in combination with reduced growth or HELPP-syndrome), preterm delivery ( $<37$ weeks of gestation), caesarean sections (primary caesarean sections and total number combining primary and secondary caesarean sections). The following neonatal pregnancy outcomes were recorded: birth weight, gestational age, sex, macrosomia (birth weight $>4 \mathrm{~kg}$ ), LGA (birth weight $>90$ percentile according to validated Flemish growth charts adjusted for sex and parity) [14], small for gestational age (birth weight $<10$ percentile according to validated Flemish growth charts adjusted for sex and parity) [14], Apgar score (five minutes), admission at the neonatal intensive care unit (NICU), hypoglycemia (defined as need of intravenous glucose) and congenital malformations.

To analyze the evolution of pregnancy outcomes over time, the 22 year period was divided in 4 different time periods. Due to changes in policy over time in our hospital, the following division was made: 1992-1998, 1999-2004 since the stricter peripartum glycemic management, 2005-2009 since most neonates stay with their mother and the last 5 years from 2010-2014.

HbA1c was during the study time period measured by different techniques. From 1992 till March 1996 a homemade method was used based on the Jeppson method (Pharmacia Mono S kolom, cation exchange). From March 1996 till May 2002 the immunoassay method Unimate HbA1c of Roche was used (Cobas Integra 400). From May 2002 till August 2007, the immunoassay method Dimension HA1Cof . Dade Behring was used. From August 2007 till August 2014, the reversed-phase cation-exchange chromatography was used (ADAMS HA-8160, Menarini Diagnostics Benelux). Since 1996 Hba1c is reported in compliance with the National Glycohemoglobin Standardization Program [15].

Lipids were during the whole study period measured by the same biomedical technique with also few changes in the calibration methods that were used. Total cholesterol was measured on Cobas 8000, Roche Diagnostics by enzymatic colorimetric CHOD-PAP method, triglycerides by enzymatic colorimetic GPO-PAP method, HDL cholesterol by dextran sulfate/Mg precipitation followed by enzymatic colorimetic CHOD-PAP reaction, calculated LDL-cholesterol by Friedewald formula (Total cholesterol-HDL cholesterol-Triglycerides / 4).

\section{Statistical analyses}

Continuous variables are presented as mean and standard deviation. Normality was assessed by graphical exploration. Categorical variables are presented as frequencies and percentages.

Logistic regression models were used to analyze the association between several clinical variables and LGA as binary outcome. A random intercept for patient was modeled to account for the fact that several pregnancies in the same women may occur in the data set. First, univariable analyzes were performed and secondly, a multivariable model was constructed using a forward model selection strategy, considering variables that resulted significant from the univariable analyzes.

To evaluate differences between 4 time periods with respect to clinical variables, generalized linear mixed models were used for binary variables, and linear mixed models for continuous variables with time period as a factor. To evaluate the relation between the BMI categories (overweight, obesity) and excessive weight gain 
generalized linear mixed models were used with BMI category as a factor.

Complete case analyses were performed, $p$-values $<0.05$ were considered significant and all tests were two-sided. Statistical analyses were performed using SPSS 22.0.

\section{Results}

After exclusion of women with late referral after 12 weeks or with follow up in another center (29), 229 women with pregestational diabetes were identified. We further excluded pregnant women with monogenetic forms of diabetes (5), T2DM (28), neonatal diabetes (1), secondary diabetes due to cystic fibrosis (2), a T1DM patient on a peritoneal insulin pump (1), early pregnancy loss due to abortion because of congenital malformations $(n=4)$, mors in utero (4) and multiple births (4). This leaves a cohort of 259 pregnancies in 180 T1DM women over a 22-year period. There were low rates of diabetic retinopathy $(2.7 \%)$, diabetic nephropathy (3.9\%), congenital malformations (2.7\%) and Apgar scores $<7$ ( $1.5 \%$ of baby's).

Table 1 gives an overview of the general characteristics of the whole cohort and the evolution over time using 4 time categories. Missing data were scarce $(<5 \%)$ except for the lipid measurements $(n=93)$ and insulin dose in the third trimester $(n=40)$. The majority of women were Caucasian with exception of 8 North African women. $11.6 \%$ of women received a fertility treatment. Insulin pumps were used in $84.6 \%$ of pregnancies. $90 \%$ of women had a preconception consultation. Despite an active policy of pregnancy planning, in $29 \%$ of pregnancies the glycemic control at time of conception was above the target HbA1c of $53 \mathrm{mmol} / \mathrm{mol}$ (7 \%). Mean diabetes duration of women was $13.7 \pm 7.1$ years with a mean age of $29.5 \pm 5.2$ years, both increased over the years. Over time, significant more women were overweight and more women had excessive weight gain during pregnancy. Over time women had a lower mean LDL cholesterol $(125.3 \pm 20.7 \mathrm{mg} / \mathrm{dL}$ vs. $89.2 \pm 25.0 \mathrm{mg} / \mathrm{dL}, \quad p=0.001)$ and lower levels of triglycerides $(118.3 \pm 60.3 \mathrm{mg} / \mathrm{dl}$ vs. $76.1 \pm 35.4 \mathrm{mg} / \mathrm{dl}$, $p=0.03)$. BMI categories overweight and obesity were both a risk factor for excessive weight gain compared to normal weight women $(\mathrm{BMI}<25)$ with an odds ratio (OR) of 4.04 (CI 2.19-7.46, $p<0.001$ ) for overweight women and an OR of 5.07 (CI 2.04-12.61, $p<0.001$ ) for obese women.

Table 2 gives an overview of the pregnancy outcomes of the whole cohort. The missing data are scarce $(<5 \%)$. Macrosomia was present in $16.2 \%$ of women, LGA was present in $45.2 \%$ and $67.2 \%$ received a cesarean section. These numbers did not change significantly over time. Neonatal hypoglycaemia decreased since 1999 due to a stricter glycaemic management peripartum. The NICU admissions decreased since 2005 due to the change in policy in our center.

Table 1 The characteristics of the whole cohort of type 1 diabetes and evolution over time

\begin{tabular}{|c|c|c|c|c|c|c|}
\hline & $1992-2014$ & 1992-1998 & 1999-2004 & $2005-2009$ & $2010-2014$ & $P$ value \\
\hline & $(n=259)$ & $(n=74)$ & $(n=64)$ & $(n=59)$ & $(n=62)$ & \\
\hline Duration of Diabetes & $13.7 \pm 7.1$ & $11.7 \pm 5.8$ & $13.7 \pm 7.5$ & $13.3 \pm 6.7$ & $15.4 \pm 8.9$ & 0.002 \\
\hline Maternal age at delivery (years) & $29.5 \pm 5.2$ & $28.7 \pm 3.9$ & $29.7 \pm 3.7$ & $29.6 \pm 4.2$ & $30.4 \pm 4.9$ & 0.03 \\
\hline Weight trimester 1 (kg) & $69.9 \pm 10.8$ & $67.8 \pm 10.0$ & $70.0 \pm 10.7$ & $71.4 \pm 10.6$ & $70.7 \pm 11.9$ & 0.003 \\
\hline Weight at delivery $(\mathrm{kg})$ & $82.1 \pm 11.1$ & $78.4 \pm 9.6$ & $83.4 \pm 11.9$ & $85.3 \pm 11.3$ & $82.3 \pm 10.7$ & 0.001 \\
\hline BMI before pregnancy $(\mathrm{kg} / \mathrm{m} 2)$ & $25.3 \pm 3.8$ & $24.9 \pm 3.7$ & $25.5 \pm 3.8$ & $25.3 \pm 3.6$ & $25.4 \pm 4.2$ & 0.12 \\
\hline Obesity & $10.9 \%(n=28)$ & $9.6 \%(n=7)$ & $14.1 \%(n=9)$ & $6.8 \%(n=4)$ & $13.1 \%(n=8)$ & 0.48 \\
\hline Overweight & $33.9 \%(n=87)$ & $23.3 \%(n=17)$ & $28.1 \%(n=18)$ & $47.5 \%(n=28)$ & $39.3 \%(n=24)$ & 0.009 \\
\hline Excessive weight gain & $34.4 \%(n=91)$ & $21.3 \%(n=15)$ & $42.2 \%(n=27)$ & $40.4 \%(n=25)$ & $37.7 \%(n=24)$ & 0.019 \\
\hline \multirow[t]{2}{*}{$\mathrm{HbA} 1 \mathrm{c}$ before pregnancy $\mathrm{mmol} / \mathrm{mol}(\%)$} & $52 \pm 10$ & $51 \pm 10$ & $53 \pm 12$ & $50 \pm 6$ & $53 \pm 12$ & \multirow[t]{2}{*}{0.24} \\
\hline & $(6.9 \pm 0.9)$ & $(6.8 \pm 0.9)$ & $(7.0 \pm 1.1)$ & $(6.7 \pm 0.6)$ & $(7.0 \pm 1.1)$ & \\
\hline \multirow[t]{2}{*}{$\mathrm{HbA} 1 \mathrm{c}$ trimester $1 \mathrm{mmol} / \mathrm{mol}(\%)$} & $49 \pm 8$ & $46 \pm 8$ & $51 \pm 11$ & $48 \pm 5$ & $50 \pm 10$ & \multirow[t]{2}{*}{0.05} \\
\hline & $(6.6 \pm 0.8)$ & $(6.4 \pm 0.8)$ & $(6.8 \pm 1.0)$ & $(6.5 \pm 0.5)$ & $(6.7 \pm 0.9)$ & \\
\hline $\mathrm{HbA1c}$ trimester 2 & $41 \pm 8$ & $39 \pm 7$ & $41 \pm 7$ & $42 \pm 7$ & $42 \pm 8$ & \multirow[t]{2}{*}{0.23} \\
\hline $\mathrm{mmol} / \mathrm{mol}(\%)$ & $(5.9 \pm 0.7)$ & $(5.7 \pm 0.7)$ & $(5.9 \pm 0.6)$ & $(6.0 \pm 0.6)$ & $(6.0 \pm 0.7)$ & \\
\hline $\mathrm{HbA1c}$ trimester 3 & $43 \pm 7$ & $41 \pm 8$ & $43 \pm 7$ & $44 \pm 5$ & $44 \pm 7$ & 0.10 \\
\hline $\mathrm{mmol} / \mathrm{mol}(\%)$ & $(6.1 \pm 0.6)$ & $(5.9 \pm 0.7)$ & $(6.1 \pm 0.6)$ & $(6.2 \pm 0.4)$ & $(6.2 \pm 0.6)$ & \\
\hline
\end{tabular}

BMI Body Mass Index, $P$ value in bold indicates a statistically significant difference between the four time periods

Results are given as mean (SD) or \% (n); Generalized linear mixed models were used for binary variables, and linear mixed models for continuous variables with time period as a factor

Bold indicates statistically significant associations, $p<0.05$ 
Table 2 The pregnancy outcomes in the whole cohort of women with type 1 diabetes and evolution over time

\begin{tabular}{|c|c|c|c|c|c|c|}
\hline Outcome & $\begin{array}{l}1992-2014 \\
(n=259)\end{array}$ & $\begin{array}{l}1992-1998 \\
(n=74)\end{array}$ & $\begin{array}{l}1999-2004 \\
(n=64)\end{array}$ & $\begin{array}{l}2005-2009 \\
(n=59)\end{array}$ & $\begin{array}{l}2010-2014 \\
(n=62)\end{array}$ & $P$ value \\
\hline \multicolumn{7}{|l|}{ WOMEN } \\
\hline Pregnancy induced hypertension & $12.7 \%(n=33)$ & $16.2 \%(n=12)$ & $21.9 \%(n=14)$ & $5.1 \%(n=3)$ & $6.5 \%(n=4)$ & 0.033 \\
\hline Pre-eclampsia & $8.1 \%(n=21)$ & $8.1 \%(n=6)$ & $4.7 \%(n=3)$ & $8.5 \%(n=5)$ & $11.3 \%(n=7)$ & 0.55 \\
\hline Preterm delivery & $19.7 \%(n=51)$ & $21.6 \%(n=16)$ & $15.6 \%(n=10)$ & $22.0 \%(n=13)$ & $19.4 \%(n=12)$ & 0.83 \\
\hline Caesarean section & $67.2 \%(n=174)$ & $68.9 \%(n=51)$ & $73.4 \%(n=47)$ & $59.3 \%(n=35)$ & $66.1 \%(n=41)$ & 0.70 \\
\hline Primary Caesarean section & $46.3 \%(n=120)$ & $52.7 \%(n=39)$ & $48.4 \%(n=41)$ & $30.5 \%(n=18)$ & $51.6 \%(n=32)$ & 0.038 \\
\hline \multicolumn{7}{|l|}{ FETAL } \\
\hline Male & $53.7 \%(n=139)$ & $47.3 \%(n=35)$ & $59.4 \%(n=38)$ & $50.8 \%(n=30)$ & $58.1 \%(n=36)$ & 0.48 \\
\hline Gestational age at birth (weeks) & $37.0 \pm 1.4$ & $36.7 \pm 1.5$ & $37.1 \pm 1.1$ & $37.2 \pm 1.5$ & $37.2 \pm 1.4$ & 0.35 \\
\hline Birth weight (g) & $3458 \pm 605$ & $3454 \pm 652$ & $3399 \pm 649$ & $3462 \pm 596$ & $3518 \pm 511$ & 0.57 \\
\hline LGA infant & $45.2 \%(n=117)$ & $50.0 \%(n=37)$ & $35.9 \%(n=23)$ & $40.7 \%(n=24)$ & $53.2 \%(n=33)$ & 0.19 \\
\hline Macrosomia & $16.2 \%(n=42)$ & $17.6 \%(n=13)$ & $15.6 \%(n=10)$ & $13.6 \%(n=8)$ & $17.7 \%(n=11)$ & 0.92 \\
\hline Admissions NICU & $66.3 \%(n=171)$ & $97.3 \%(n=72)$ & $79.7 \%(n=51)$ & $40.7 \%(n=24)$ & $39.3 \%(n=24)$ & 0.001 \\
\hline Neonatal hypoglycaemia & $29.0 \%(n=67)$ & $42.6 \%(n=20)$ & $28.6 \%(n=18)$ & $25.4 \%(n=15)$ & $22.6 \%(n=14)$ & 0.18 \\
\hline
\end{tabular}

NICU neonatal intensive care unit, LGA large-for-gestational age infant

Results are given as mean (SD) or \% ( $\mathrm{n}) ; P$ value in bold indicates a statistically significant difference between the four time periods. Generalized linear mixed models were used for binary variables, and linear mixed models for continuous variables with time period as a factor

The difference in characteristics between LGA and non-LGA pregnancies are summarized in Table 3. In the univariable analysis, compared to women with a nonLGA baby, women with a LGA baby had a significantly higher weight at delivery and had significantly more often excessive weight gain. HbA1c in the first and third trimester was also significantly higher in women with a LGA baby. No significant differences in BMI before pregnancy ( $25.2 \pm 3.7$ vs. $25.3 \pm 3.8, p=0.80)$, duration of diabetes (13.7 \pm 6.7 years vs. $13.7 \pm 7.4$ years, $p=0.99)$, age at delivery ( $29.5 \pm 4.1$ years vs. $29.6 \pm 4.3$ years, $p=0.92)$, smoking habits ( $11.1 \%$ vs. $18.3 \%, p=0.28)$, preconception consultation (90.6 \% vs. $89.4 \%, p=0.65)$ and lipid levels (LDL cholesterol $87 \pm 28 \mathrm{mg} / \mathrm{dl}$ vs $91 \pm 28 \mathrm{mg} / \mathrm{dl}, p=0.70$, triglycerides $79 \pm 36 \mathrm{mg} / \mathrm{dl}$ vs. $85 \pm 41, p=0.60$ ) were seen between LGA and non-LGA groups. Using a forward model selection strategy, the following variables that resulted significant from the univariable analyzes were included in the multivariable model: weight at delivery, weight gain during pregnancy, excessive weight gain and HbA1c during the first, second and third trimester of pregnancy. In the forward multivariable analysis, excessive weight gain ( $p=0.027$, OR 1.95 , CI 1.08-3.53), HbA1c level in early ( $p=0.023$, OR 1.43 , CI $1.05-1.95)$ and late pregnancy $(p=0.026$, OR 1.70, CI $1.07-2.71)$ remained independent predictors for LGA.

Based on a receiver operating characteristics (ROC) curve for $\mathrm{HbA1c}$ in the first trimester with an area under the curve (AUC) of 0.589 , a HbA1c $\geq 40 \mathrm{mmol} /$ mol (5.8\%) had the best sensitivity and specificity combined of resp. $94,5 \%$ and $12,7 \%$ to predict a LGA outcome but with a low positive predictive value of $47.7 \%$. Based on a ROC curve for HbA1c in the third trimester with an AUC of 0.584 , a $\mathrm{HbA} 1 \mathrm{c} \geq 36 \mathrm{mmol} /$ mol (5.4 \%) had the best sensitivity and specificity combined of resp. $97,1 \%$ and $13,4 \%$ to predict a LGA outcome but with a low positive predictive value of $47.6 \%$.

\section{Discussion}

We show that LGA remains a frequent complication in T1DM. Our study shows that excessive weight gain and HbA1c in early and late pregnancy are independent risk factors for LGA in our population. Despite a generally good glycemic control, the prevalence of overweight women and excessive weight gain during pregnancy increased over the years in our population. Studies in women with pregestational diabetes or gestational diabetes confirm the strong association between obesity, excessive weight gain in pregnancy and fetal overgrowth $[9,10,16]$. Compared to women with T2DM, women with T1DM have generally a higher diabetes duration, a more variable glycaemic control and therefore often a higher HbA1c during pregnancy [17]. More data are therefore necessary to evaluate whether overweight and excessive weight gain are also independent predictors for LGA in women with T1DM. Recently a Danish observational study in 115 women with T1DM identified excessive weight gain during pregnancy as an independent risk factor for fetal overgrowth in T1DM [12]. Our study in a cohort of 259 pregnancies with T1DM shows a high rate of excessive weight gain during pregnancy and 
Table 3 The difference in maternal characteristics between LGA and non-LGA pregnancies

\begin{tabular}{|c|c|c|c|c|c|}
\hline \multirow[t]{2}{*}{ Predictor } & \multirow{2}{*}{$\begin{array}{l}\text { LGA } \\
(n=117)\end{array}$} & \multirow{2}{*}{$\begin{array}{l}\text { Non LGA } \\
(n=142)\end{array}$} & \multirow[t]{2}{*}{ OR } & \multirow[t]{2}{*}{$\mathrm{Cl}$} & \multirow[t]{2}{*}{$P$ value } \\
\hline & & & & & \\
\hline Weight first visit (kg) & $70.9 \pm 10.6$ & $69.0 \pm 10.9$ & 1.01 & $0.99-1.04$ & 0.25 \\
\hline Weight at delivery (kg) & $84.1 \pm 11.1$ & $80.4 \pm 10.8$ & 1.03 & $1.01-1.06$ & 0.016 \\
\hline BMI before pregnancy (kg/m2) & $25.2 \pm 3.7$ & $25.3 \pm 3.8$ & 0.99 & $0.92-1.06$ & 0.80 \\
\hline Obesity $^{a}$ & $11.1 \%(n=13)$ & $10.7 \%(n=15)$ & 1.01 & $0.44-2.32$ & 0.99 \\
\hline Overweight $^{a}$ & $32.5 \%(n=38)$ & $35.0 \%(n=49)$ & 1.29 & $0.76-2.18$ & 0.35 \\
\hline Weight gain during pregnancy (kg) & $13.2 \pm 4.8$ & $11.4 \pm 5.2$ & 1.08 & $1.02-1.13$ & 0.008 \\
\hline Excessive weight gain & $45.3 \%(n=53)$ & $25.2 \%(n=38)$ & 2.22 & $1.29-3.70$ & 0.003 \\
\hline \multirow[t]{2}{*}{$\mathrm{HbA} 1 \mathrm{c}$ before pregnancy $\mathrm{mmol} / \mathrm{mol}(\%)$} & $53 \pm 10$ & $51 \pm 11$ & 1.28 & $0.95-1.72$ & 0.10 \\
\hline & $(7.0 \pm 0.9)$ & $(6.8 \pm 1.0)$ & & & \\
\hline \multirow[t]{2}{*}{$\mathrm{HbA} 1 \mathrm{c}$ trimester $1 \mathrm{mmol} / \mathrm{mol}(\%)$} & $50 \pm 10$ & $48 \pm 8$ & 1.49 & $1.10-2.02$ & 0.010 \\
\hline & $(6.7 \pm 0.9)$ & $(6.5 \pm 0.8)$ & & & \\
\hline \multirow[t]{2}{*}{$\mathrm{HbA} 1 \mathrm{c}$ trimester $2 \mathrm{mmol} / \mathrm{mol}(\%)$} & $42 \pm 7$ & $40 \pm 8$ & 1.61 & $0.98-2.65$ & 0.06 \\
\hline & $(6.0 \pm 0.6)$ & $(5.8 \pm 0.7)$ & & & \\
\hline \multirow[t]{2}{*}{$\mathrm{HbA} 1 \mathrm{c}$ trimester $3 \mathrm{mmol} / \mathrm{mol}(\%)$} & $44 \pm 6$ & $42 \pm 7$ & 1.82 & $1.16-2.86$ & 0.010 \\
\hline & $(6.2 \pm 0.5)$ & $(6.0 \pm 0.6)$ & & & \\
\hline $\mathrm{HbA} 1 \mathrm{c}<42 \mathrm{mmol} / \mathrm{mol}(6 \%)$ trimester 1 & $12.7 \%(n=14)$ & $25.4 \%(n=35)$ & 0.47 & $0.26-0.86$ & 0.015 \\
\hline $\mathrm{HbA} 1 \mathrm{c}<42 \mathrm{mmol} / \mathrm{mol}(6 \%)$ trimester 2 & $50.9 \%(n=56)$ & $67.4 \%(n=93)$ & 0.47 & $0.27-0.80$ & 0.005 \\
\hline $\mathrm{HbA} 1 \mathrm{c}<42 \mathrm{mmol} / \mathrm{mol}(6 \%)$ trimester 3 & $30.1 \%(n=31)$ & $40.9 \%(n=52)$ & 0.61 & $0.37-1.02$ & 0.06 \\
\hline
\end{tabular}

LGA large-for-gestational-age infant, BMI Body Mass Index

Results are given as mean (SD) or \% (n); Bold indicates statistically significant associations, $p<0.05$

Odds ratio (95\%)

a reference category: normal weight with $\mathrm{BMI}<25 \mathrm{~kg} / \mathrm{m} 2$

Logistic regression models were used to analyze the association between several clinical variables and LGA as binary outcome

confirms the impact of excessive weight gain on fetal overgrowth, independent of maternal glycemic control in early and late pregnancy in T1DM. In addition, our study shows that overweight and obese women often have the highest prevalence of excessive weight gain. This highlights the need for individualized preconception counseling to limit weight gain in these women [18].

In GDM maternal lipids in the third pregnancy trimester have also been shown to be strong determinants of fetal growth [19]. Our study found no relationship between lipid profile and LGA, possibly due to the high number of missing data on the lipid profile.

Glycemic control in early and late pregnancy are major risk factors for LGA in our study population. The majority of our T1DM population was treated with an insulin pump and the glycemic control in our cohort was generally appropriate. However more data are necessary on the most optimal glycemic targets in each trimester. A large prospective study with $>700$ women with T1DM showed significant increasing rates of LGA with an $\mathrm{HbA} 1 \mathrm{c} \geq 42 \mathrm{mmol} / \mathrm{mol}(6,0 \%)$ at 26 and 34 weeks gestation [20]. In our study, the highest sensitivity to predict LGA was seen at an HbA1c $<42 \mathrm{mmol} / \mathrm{mol}(6 \%)$ but with a low positive predictive value. Such a strict glycemic control is often challenging to reach since insulin is associated with an increased risk for hypoglycemia and weight gain [21]. New technologies might help to improve pregnancy outcomes but there is currently insufficient evidence that intermittent use of real-time continuous glucose monitoring in T1DM pregnancies can improve pregnancy outcomes [22].

Overweight and obesity are becoming an pandemic problem. In our study the number of overweight T1DM women almost doubled during the study period. This is twice as high as seen in the background population in Flanders [23]. In contrast, the rate of obesity remained stable through the years, similar with the frequency seen in healthy pregnant women in Flanders [23]. Both GDM and maternal obesity are independently associated with adverse pregnancy outcomes [24]. In a large database of 3457 T1DM pregnancies the incidence of LGA increased with greater BMI category [11]. In our study BMI was not an independent risk factor for LGA but this might be due to the rather small number of obese women in our cohort.

Strengths of the study are the detailed characterization of a large cohort with T1DM over more than 20 years. A multivariable model was used to evaluate independent risk factors for LGA. A limit of the study is the retrospective nature of the analysis. However most data were 
collected prospectively. In our cohort we included women with diabetic nephropathy and pre-eclampsia, which might have underestimated the LGA rate since these conditions have a restrictive impact on birth weight. However numbers were small and this is therefore unlikely to have an impact on the risk factors for LGA. Whether the results are applicable to other populations with T1DM needs to be further explored. Our population consists of relative healthy T1DM patients with generally a good glycemic control and low prevalence of obesity.

\section{Conclusions}

LGA remains a frequent complication in T1DM. Excessive weight gain and HbAlc in early and late pregnancy are important risk factors for LGA in our population. Our findings highlight the importance of strict maternal glycemic control during pregnancy and simultaneous striving to appropriate gestational weight gain to minimize the risk of fetal overgrowth in T1DM pregnancies.

\section{Abbreviations}

$\mathrm{BMI}$, body mass index; GDM, gestational diabetes; HbA1c, hemoglobin A1c; $1 \mathrm{OM}$, institute of medicine; LGA, large-for-gestational age; MDI, multiple daily injections; $\mathrm{NICU}$, neonatal intensive care unit; $\mathrm{OR}$, odds ratio; $\mathrm{PIH}$, pregnancy induced hypertension; T1DM, diabetes mellitus type 1; T2DM, diabetes mellitus type 2

\section{Acknowledgements}

$\mathrm{KB}$ is the recipient of a Clinical Doctoral Scholarship (KOF) of the university hospital UZ Gasthuisberg and RD is the recipient of a 'Fundamenteel Klinisch Navorserschap FWO Vlaanderen'. Annouschka Laenen and Johan Rys contributed to the statistical analysis.

\section{Funding}

This work was not funded.

\section{Availability of data and materials}

All available data are provided in the main manuscript.

\section{Authors' contributions}

$\mathrm{AM}, \mathrm{KB}, \mathrm{JV}, \mathrm{CV}, \mathrm{RD}$ and $\mathrm{CM}$ have made substantial contributions to the conception of the study and have been involved in drafting the manuscript. AM and JV have collected the data. AM performed the statistical analysis. $A M, J V, C V, R D, K B$ and $C M$ have been involved in revising it critically for important intellectual content. All authors have given final approval of the version to be published.

\section{Competing interests}

The authors declare that they have no competing interests.

\section{Consent for publication}

Not applicable.

\section{Ethics approval and consent to participate}

All procedures followed were in accordance with the ethical standards of the responsible committee on human experimentation (institutional and national) and with the Helsinki Declaration of 1975, as revised in 2008. Since the data were analyzed retrospectively, no informed consent was needed.

\section{Author details}

'Department of Endocrinology, UZ Gasthuisberg, KU Leuven, Herestraat 49, Leuven 3000, Belgium. ²Department of Obstetrics \& Gynecology, UZ Gasthuisberg, KU Leuven, Herestraat 49, Leuven 3000, Belgium. ${ }^{3}$ Department of Pediatrics, UZ Gasthuisberg, KU Leuven, Herestraat 49, Leuven 3000 , Belgium.
Received: 12 December 2015 Accepted: 9 July 2016

Published online: 15 July 2016

\section{References}

1. Casson IF, Clarke CA, Howard CV, McKendrick O, Pennycook S, Pharoah PO, et al. Outcomes of pregnancy in insulin dependent diabetic women: results of a five year population cohort study. BMJ. 1997;315:275.

2. Penney GJ, Mair G, Pearsen DW. Outcomes of pregnancies in women with type 1 diabetes in Scotland: a national population-based study. BJOG. 2003; 110:315-8.

3. Evers IM, de Valk HW, Visser GH. Risk of complications of pregnancy in women with type 1 diabetes: nationwide prospective study in the Netherlands. BMJ. 2004:328(7445):915.

4. Persson M, Norman M, Hansen U. Obstetric and perinatal outcomes in type 1 diabetic pregnancies. Diabetes Care. 2009:32:2005-9.

5. Clausen TD, Mathiesen ER, Hansen T, Pedersen O, Jensen DM, Lauenborg J, et al. High prevalence of type 2 diabetes and prediabetes in adult offspring of women with gestational diabetes mellitus of type 1 diabetes: the role of intrauterine hyperglycemia. Diabetes Care. 2008;31:340-6.

6. The Diabetes Control and Complications Trial Research Group. The effect of intensive treatment of diabetes on the development and progression of long-term complications in insulin-dependent diabetes mellitus. The Diabetes Control and Complications Trial Research Group. N Engl J Med. 1993;329(14):977-86.

7. Tanvig M, Wehberg S, Vinter CA, Joergensen JS, Ovesen PG, Beck-Nielsen H, et al. Pregestational body mass index is related to neoantal abdominal circumference at birth - a Danish popualtion-based study. BJOG. 2013; 120:320-30.

8. Nohr EA, Vaeth M, Baker JL, Sorensen TI, Olsen J, Rasmussen KM. Combined associations of prepregnancy body mass index and gestational weight gain with the outcome of pregnancy. Am J Clin Nutr. 2008:87:1750-9.

9. Parellada CB, Asbjornsdottir B, Ringholm L, Damm R, Mathiesen ER. Fetal growth in relation to gestational weight gain in women with Type 2 diabetes: an observational study. Diabet Med. 2014;31:1681-9.

10. Ray JG, Vermeulen MJ, Shapiro JL, Kenshole AB. Maternal and neonatal outcomes in pregestational and gestational diabetes mellitus, and the influence of maternal obesity and weight gain: the DEPOSIT study. Q J Med. 2001;94:347-56

11. Persson M, Pasupathy D, Hanson U, Westgren M, Norman M. Pre-pregnancy body mass index and the risk of adverse outcome in type 1 diabetic pregnancies: a population-based cohort study. BMJ Open. 2012;2(1): e000601.

12. Secher AL, Parellada CB, Ringholm L, Asbjornsdottir B, Damm P, Mathiesen ER. Higher gestational weight gain is associated with increasing offspring birth weight independent of maternal glycemic control in women with type 1 diabetes. Diabetes Care. 2014;37:2677-84.

13. Institute of Medicine (US) and National Research Council (US) Committee to Reexamine IOM Pregnancy Weight Guidelines. Weight gain during pregnancy: reexamining the guidelines. In: Rasmussen KM, Yaktine AL, editors. National Academies Press (US). Washington (DC): The National Academies Collection: Reports funded by National Institutes of Health; 2009.

14. Devlieger H, Martens G, Bekaert A, Eeckels R. Standaarden van geboortegewicht voor zwangerschapsduur voor de Vlaamse boreling. Tijdschr Geneesk. 2000;56:1-14.

15. Little RR, Rohlfing CL, Sacks DB. Status of HbA1c measurement and goals for improvement: From chaos to order for improving diabetes care. Clin Chem. 2011;57:204-14.

16. Egan AM, Dennedy MCD, Al-Ramli W, Heerey A, Avalos G, Dunne F. ATLANTIC-DIP: Excessive gestational weight gain and prepregnancy outcomes in women with gestational or pregestational diabetes mellitus. J Clin Endocrinol Metab. 2014;99(1):212-9.

17. Balsells M, García-Patterson A, Gich I, Corcoy R. Maternal and fetal outcome in women with type 2 versus type 1 diabetes mellitus: a systematic review and metaanalysis. J Clin Endocrinol Metab. 2009;94(11):4284-91.

18. Deputy PN, Sharma AJ, Kim SY, Hinkle SN. Prevalence and characteristics associated with gestational weight gain adequacy. Obstet Gynaecol. 2015;125:773-81.

19. Schaefer-Graf UM, Graf K, Kulbacka I, Kjos SL, Dudenhaysen J, Vetter K et al. Maternal lipids as strong determinants of fetal environment and growth in pregnancies with gestational diabetes mellitus. Diabetes Care. 2008;31:1858-63. 
20. Maresh MJA, Holmes VA, Patterson CC, Young IS, Pearson DWM, Walker JD, Diabetes and Pre-eclampsia Intervention Trial Study Group, et al. Glycemic targets in the Second and Third trimester of Pregnancy for Women With Type 1 Diabetes. Diabetes Care. 2015;38:34-40.

21. Wahabi HA, Alzeidan RA, Esaeil SA. Pre-pregnancy care for women with pre-gestational diabetes mellitus: a systematic review and meta-analysis. BMC Public Health. 2012;12:792.

22. Secher AL, Ringholm L, Andersen HU, Damm P, Mathiesen ER. The effect of real-time continuous glucose monitoring in pregnant women with diabetes: a randomized controlled trial. Diabetes Care. 2013;36:1877-83.

23. Bogaerts A, Devlieger R, Van den Bergh BR, Witters I. Obesity and pregnancy, an epidemiological and intervention study from a psychosocial perspective. Facts Views Vis Obgyn. 2014;6(2):81-95.

24. Catalano PM, Mclntyre HD, Cruickshank JK, McCance DR, Dyer AR, Metzger BE, HAPO Study Cooperative Research Group, et al. The Hyperglycemia and adverse pregnancy outcome study. Associations of GDM and obesity with pregnancy outcomes. Diabetes Care. 2012;35:780-6.

Submit your next manuscript to BioMed Central and we will help you at every step:

- We accept pre-submission inquiries

- Our selector tool helps you to find the most relevant journal

- We provide round the clock customer support

- Convenient online submission

- Thorough peer review

- Inclusion in PubMed and all major indexing services

- Maximum visibility for your research

Submit your manuscript at www.biomedcentral.com/submit
Biomed Central 